\title{
A teoria da complexidade e o seu princípio educativo: as ideias educacionais de Edgar Morin
}

\author{
Bruno Pedroso Lima Silva*
}

\begin{abstract}
Resumo
Esse artigo tem o objetivo de apresentar, discutir e demonstrar os elementos estruturantes da teoria da complexidade, analisando-a desde suas ideias sobre a sociedade, a ciência e a vida, até sua ênfase na importância da compreensão de mundo sistêmica e complexa no processo educativo. Apoiando-me em seu principal expoente, o francês Edgar Morin, faço uma introdução às ideias da complexidade como teoria filosófica, pensando a ciência e as consequências que seus paradigmas trazem para a formaçáo da ordem social e da compreensão da vida, da cultura e da natureza. Após isso, discuto as ideias educativas de Morin, enfatizando, com ele, a necessidade de o processo de compreensáo do mundo se iniciar no âmbito da educação, através da conscientização e do estímulo à autonomia e à crítica. Nessa perspectiva, também apresento e discuto o que Morin chamou de "os sete saberes necessários à educação do futuro", um tipo de sistematização feita pelo autor de suas ideias educativas, imaginando a quebra dos paradigmas científico-sociais vigentes e pensando na educação como esperança de uma consequente transformação social em longo prazo.
\end{abstract}

Palavras-chave: complexidade, ciência, educação, mudança, filosofia.

\section{Complexity theory and its educational principle: Edgar Morin's educational ideas}

\begin{abstract}
This article sets out to present, discuss and show the structuring elements of complexity theory by analyzing it from its ideas about society, science and life to its emphasis on the importance of understanding the systemic and complex world in the educational process. Using its main exponent, the French author Edgar Morin as a support, I present an introduction to the ideas of complexity as a philosophical theory, thinking of science and the consequences that its paradigms have for the formation of social order and an understanding of life, culture and nature. After that, I dialogue with Morin about his ideas on education, emphasizing, as he does the need for the process of complex understanding of the world beginning in the sphere of education through raising awareness and encouraging autonomy and critique. From this perspective, I also present and discuss what Morin called "The seven complex lessons in education for the future", a kind of systematization which the author made of his theory of
\end{abstract}

* Mestrando em Educação Brasileira, Faculdade de Educação/UFG. E-mail: brunoplsilva@yahoo. com.br 
knowledge, on imagining the breakdown of existing socio-scientific paradigms and thinking of education as hope for subsequent long-term social transformation.

Keywords: complexity, science, education, change, philosophy.

\section{Introdução}

Na etimologia, "complexidade" vem do latim complexus, que significa "o que é tecido em conjunto". Nessa definição, já se tem uma ideia do pensamento básico dessa teoria: a junção, o conjunto, o universo, a noção de que tudo está ligado, influi e é influenciado por tudo. A teoria da complexidade, também chamada apenas de "complexidade", de "pensamento complexo" ou até de "epistemologia da complexidade" é então uma noção, um pensamento filosófico e epistemológico que tem como grande pilar estruturante a transdisciplinaridade. A complexidade busca conceber uma visão conjunta entre as diversas áreas de estudo para pensar, de forma questionadora, com um olhar inquiridor, a natureza, a realidade, a vida, o mundo. Sua epistemologia é audaciosa: a proposta é criar uma "epistemologia da epistemologia", ou seja, pensar o conhecimento, colocar o próprio conhecimento como objeto. Para isso, a complexidade tem uma visão dotada de uma fervorosa crítica aos paradigmas de pensamento e de conhecimento que temos hoje, decorrentes da modernidade, e pretende, com essa crítica, pensar, refletir e apontar as falhas nesses modelos vigentes, propondo entâo uma transformação que Edgar Morin (1991) chama de "reforma do pensamento", capaz de nos levar, de forma transdisciplinar, à verdadeira compreensão do real.

Justifico a minha escolha de trabalhar neste ensaio apenas com as ideias de Edgar Morin a partir do seguinte princípio: do meu ponto de vista, a multiplicidade de ideias em relação a uma teoria ou visão sobre a sociedade, a discussão, a atualização e a contextualizaçâo de autores clássicos - apesar de ser isso inegavelmente importante e trazer uma riqueza de conhecimentos -, acabam, em alguns casos, por descaracterizar os fundamentos estruturantes do(s) autor(es) da teoria em estudo. Isso sempre me incomodou muito como pesquisador, e podemos ver claramente acontecendo no caso dos "marxismos", dos diversos "tipos de fenomenologia", dos "cartesianismos", entre outros exemplos. Acredito na importância de trabalhos como esse que apresento, que se mantém no que foi escrito e teorizado pelo principal clássico da teoria, o que pode evitar essas descaracterizaçóes, as precipitaçóes 
e os erros de colocação relativos a esses autores. Sendo Edgar Morin o teórico sistematizador da teoria da complexidade, o que primeiro teorizou sobre a complexidade de maneira ampla - e que de forma mais completa o fez em minha opiniáo -, dedico este artigo a apresentar suas ideias, na sua amplitude, mas enfatizando o foco dado pelo autor ao processo educativo.

Morin acredita que a ciência moderna se equivocou quando pensou em separação ao invés de apenas distinção. Ao criticar de forma muito dura os paradigmas medievais, a ciência moderna nasce querendo ser o contrário do paradigma medieval, rejeitá-lo completamente, surgindo entáo com um ímpeto de separação, de dualismo, de isolamento. Nasce já como a dona da verdade, separada da filosofia, das artes e até da política. Essa ideia de ciência se expandiu rapidamente, pois o contexto sócio-histórico da época - séculos XVII e XVIII - permitiu esse avanço, favorecido pelas revoluçóes burguesas, que viam nessa noção de ciência o favorecimento de seus interesses (MORIN, 1991).

Essa noção de ciência quantitativa, exata, impositiva, favorecia os interesses das classes que estavam emergindo para se tornarem poderosas. Essa rápida expansáo e o grande poder adaptativo de seus critérios metodológicos levaram à formação de um grande paradigma, principalmente no Ocidente, que tem como principal característica, como dito acima, a separação entre as áreas, o reducionismo e o simplismo exagerado. Morin chama esse paradigma de "disjuntor-redutor" (MORIN, 1991), porque separa (disjunta) ciência de um lado e filosofia e todo o tipo de conhecimento não quantificável de outro; e porque reduz o que é complexo com a ideia de simplificaçáo. Esse pensamento simplifica a realidade, é considerado como de fácil compreensão, como confiável, ganhando o espaço que pertenceu ao pensamento religioso e dogmático na Idade Média.

Diversas áreas de estudos já demonstraram que esse pensamento científico é insuficiente para a compreensão do universo da vida, do mundo e da natureza. A física subatômica instaurou a figura da incerteza no pensamento reducionista. A fenomenologia declara o positivismo como ingênuo, ao analisar sua pretensão de isolar um objeto e tirar dele a verdade sem levar em conta a subjetividade. A partir do século XX, ciências chamadas de pós-modernas, como a cosmologia e sobretudo a ecologia, aparecem como formas de conhecimento que exigem a pluridisciplinaridade, o pensamento complexo, a reflexão universal. Partindo entáo da física subatômica e da fenomenologia, e tendo como grande baque a emergência e a conquista de 
espaço de ciências como a ecologia e a cosmologia, o paradigma científico cartesiano começa a ter seu fim pensado, imaginado. Nesse contexto, surge Edgar Morin e sua teoria complexa.

Morin vê o mundo como um todo indissociável, onde, como repete ele incansavelmente, a partir de Pascal, "as partes se encontram no todo e o todo se encontra em cada uma das partes" (MORIN, 1991, 2003, 2007). Pensando uma abordagem multirreferencial e transdisciplinar de todos os fenômenos, o autor propóe uma mudança de paradigma da construção do conhecimento. Ao abandonar o reducionismo, a disjunção e a especialização dos saberes, o conhecimento abriria espaço para a criatividade, a subjetividade e um tipo de organizaçáo que poderia ser chamado de ordem desorganizada, pensado a partir da ideia do caos (MORIN, 2003).

Assim emerge o pensamento complexo, visando associar sem fundir, visando não separar as diversas disciplinas, áreas de estudo e formas de ciência, abrindo espaço para a emergência de novas formas de conhecimento e de compreensão da realidade. Vê-se, com isso, que o pensamento complexo não se limita ao âmbito acadêmico: ele questiona todas as formas de pensamento na sociedade, mergulha na reflexão sobre o Estado, o mercado, a sociedade, a religiāo, a cultura, enfatizando, a partir de todos esses preceitos, a educação.

Esse foi basicamente o caminho percorrido pelo pensamento complexo até os dias de hoje. Não se pode rotular a complexidade como um pensamento antigo, moderno ou pós-moderno. O caminho da complexidade se fez e está sendo feito a partir de princípios tanto antigos, quanto modernos e pós-modernos, e está constantemente se criando e recriando, formulando e fortalecendo suas ideias a partir do seu próprio caminhar, se fazendo e refazendo continuamente, estruturando cada vez mais o caráter de mutabilidade que essa filosofia quer demonstrar existir também na ciência como um todo.

\section{A metodologia da complexidade}

A palavra "complexidade", além de sua raiz etimológica já mostrada neste trabalho, surgiu, através do pensamento de Morin sobre uma das mais importantes categorias de sua reflexão, que ele chama de autoorganização (MORIN, 1991, 2003). Refletindo sobre as mais diversas áreas de estudo, principalmente a teoria dos sistemas, a teoria da informaçáo e a cibernética, Morin chegou ao conceito de auto-organização, que é um 
grande centro organizador de seu pensamento: a sociedade, as pessoas, a ciência, a natureza, e tudo mais que nos cerca, possuem a capacidade de se auto-organizar, através de processos de recriação e realimentação, não sendo possível, portanto, trabalhar na questão do conhecimento com métodos concretos, petrificados e imutáveis. O conhecimento, no paradigma por ele pensado, surge a partir do exercício dialógico.

O operador metodológico da complexidade é entáo dialógico e náo dialético. Entrelaça coisas que estão separadas: razão e emoção, sensível e inteligível, ciência e arte. Mas não pensa na existência de uma síntese resultante da tese e da antítese. Tudo consiste no dialogizar, sem qualquer organizaçáo programada. A complexidade trata de estabelecer uma relação dialógica com o real, um pensamento capaz de pensá-lo criticamente e de dialogar com ele.

Mesmo tendo surgido há pouco tempo, considerando o contexto histórico de outras diferentes teorias epistemológicas, a complexidade já vê com preocupação algumas ilusóes que surgem a partir de uma compreensão enganosa da teoria. Morin acredita que, para haver a compreensão real do pensamento e da proposta da complexidade, é necessário que se dissipem essas ilusôes, que ele acredita serem principalmente duas: a) a ideia de que a complexidade elimina a simplicidade. A complexidade, diz ele, aparece onde a simplificação falha, onde o simples não é suficiente para a compreensão; o complexo deve aparecer quando a simplificação se torna exagerada e acaba incorrendo na desintegraçáo do real; e b) a confusáo entre complexidade e completude (MORIN, 1991). O pensamento complexo, defende o autor, sabe, desde o início, que o conhecimento completo é impossível; o que ele pretende é recusar o saber parcelado, que não se relaciona, não se integra e se considera como um fim em si mesmo. É contra isso que o pensamento multidimensional surge, para buscar uma compreensão mais verdadeira do real, e não para ter a verdade total, o conhecimento verdadeiro, a soluçâo para tudo.

Por isso, Morin se posiciona totalmente contra o conceito de razão totalitária. O autor acredita que houve uma "fanatizaçáo" do conceito de razão, colocando-se esse conceito em um pedestal santo, como uma coisa a que todos devessem buscar, e a quem acabou se atribuindo o dever de dizer o que é ou não é verdade, o que é, ou não, erro e ilusão (MORIN, 2007). Ao criticar o conceito de razão no paradigma científico moderno, Morin lembra que ele surgiu como uma forma de quebrar mitos, de se livrar das trevas, para buscar a luz, lema do Iluminismo do século XVIII. 
Mesmo assim, tanto no século XVIII quanto atualmente, a ignorância, as ilusôes e os erros persistem. Continuam aparecendo e de forma cada vez mais grave, trazendo consequências cada vez piores para a ordem social. Por isso, ele acredita que o erro maior não está nas ilusóes, nas falsas percepções e nem na falta de conceitos que tragam o conhecimento para o âmbito subjetivo. O erro - e isso ele defende durante toda sua obra - está na organização do nosso saber, disciplinar, hierárquico, linear e simplista, organização transformada em modelo hegemônico por meio do paradigma cartesiano. Esse tipo de organização do saber favorece o surgimento de teorias fechadas em si mesmas, de ideologias que náo admitem contato com outras ideias; enfim, são a causa da hiperespecialização dos saberes que vemos acontecer em nossos dias.

Ele vê entáo o surgimento de uma nova ignorância a partir do desenvolvimento da própria ciência moderna e de seu conceito de razáo, que surgiu exatamente para evitar ignorâncias (MORIN, 2003). Essa ignorância seria um tipo de cegueira, que se apresenta a partir do uso degradado e desregrado da razão. Volta-se à ideia da caverna de Platáo, onde os seres humanos vivem em um mundo de sombras, incapazes de virar o seu pescoço e ver o mundo por completo, sem condiçóes de estabelecer uma ligação com o real. Morin $(1991,2007)$ é enfático nesse ponto: a ameaça mais grave para a humanidade é o progresso cego e descontrolado da ideia e dos modelos de conhecimento.

\section{A “ordem desorganizada": a organizaçáo do conhecimento em um paradigma complexo}

Para Morin, o conhecimento se organiza, no geral, a partir de seleçáo de dados significativos e da rejeição de dados não significativos. Mas, segundo ele, esse processo, no contexto de uma sociedade que oferecia base para isso, evoluiu de modo a centralizar, separar e hierarquizar dados e informaçóes e, automatica e acriticamente, rejeitar outros, partindo de operaçóes consideradas lógicas (MORIN, 1991, 2003). Isso resultou no que conhecemos hoje como paradigmas de organização do pensamento e do conhecimento, princípios que acabam por governar nossas ideias e visão sobre o mundo, a vida e a natureza.

Morin náo nega que esse paradigma cartesiano permitiu grandes avanços científicos e até mesmo filosóficos, mas acredita que ele trouxe 
consequências nocivas. Respeitando o que ele acredita ser um processo cíclico, esse modelo de pensamento e de organização de conhecimento deve ser superado com urgência, dando lugar a um paradigma mais atual, mais contemporâneo, que respeite os avanços da filosofia, das artes e das diversas ciências, que, cada vez mais, mostram que é necessária uma consciência mais aberta, que foque o universal, o multidimensional, o todo.

O que Morin pensa constitui, pois, uma transformação radical de paradigmas, a busca de uma lógica de pensamento e de organização de informaçáo que religue, relacione, una e veja o mundo e a vida como todos universais, que influenciam e são influenciados por tudo que nos cerca. Para ele é necessário evitar completamente a visão unidimensional, o que só conseguiremos a partir de uma consciência da natureza, do planeta e do universo da vida, e também das consequências que esses paradigmas atuais trazem para nossa compreensão desfigurada do real (MORIN, 1991, 2003, 2007).

A partir da desfiguração do real estabelecida pela ciência hegemônica, o homem não tem mais a capacidade de conhecer a si mesmo, como pensava o grande filósofo grego Sócrates. É impossível, como ele pensava, conhecer a si mesmo a partir da compreensão do mundo e do universo e a partir de sua própria reflexão, se a compreensão de realidade é desfigurada, ilusória, falsa. Nessa perspectiva, Morin analisa também a tão recorrente crítica à mídia como produtora de uma consciência moldada, abstrata e simplista. Essa crítica, pensa ele, é correta, mas é necessária a ênfase em um aspecto mais profundo. E é nesse ponto que Morin estrutura o seu pensamento educacional, exigindo mais esforços na crítica à formação como um todo, à universidade e ao ensino, que formam mentes que aceitam a alienaçáo, a falta de autonomia, o comodismo; enfim, mentes que aceitam verdades impostas, problemas que são colocados, recorrentemente, como culpa da mídia (MORIN, 2007).

Assim, a mudança de paradigma pensada por ele - de um modelo disjuntor/redutor para um modelo distintor/conjuntor - que distinga sem separar, que associe sem reduzir, começa na educação. O primeiro passo para a compreensão e consequente expansão desse pensamento dialógico é a consciência real dos problemas - Morin chega a usar a palavra "patologias" - no paradigma vigente de organização do pensamento e do conhecimento, que tem como culpados, principalmente, o doutrinarismo e o dogmatismo (MORIN, 1991). A "cura", então, para ele, é o pensamento complexo, um 
modelo de pensar que una, religue e crie novas organizaçóes e formas de socialização do conhecimento. Isso resulta, para Morin, no que ele chama de fenômeno de "auto-eco-organização", uma auto-organização que se baseie nos sistemas ecológicos, o que, para ele, deve ser inerente à vida humana, já que esse fenômeno traz consigo liberdade e autonomia (MORIN, 1991, 2003). Daí, a convicção de que todo o pensamento da complexidade precisa começar no processo educativo.

\section{Complexidade e educaçáo: as ideias educacionais de Edgar Morin}

Edgar Morin pensa e teoriza, de forma propositiva sobre a mudança no sistema educacional hegemônico ocidental. Ele chama essa mudança de reforma na educação, que é pensada com base em uma premissa principal: qualquer reforma da educação precisa começar pela reforma dos educadores (MORIN, 2007). Por essa razão, seu pensamento passa muito pela questão da reforma da universidade, onde são formados os educadores que atuarão no ensino básico e também no próprio ensino universitário.

Segundo Morin (2007), a universidade é a guardiã da herança cultural. Ela reexamina a cultura, atualiza-a e transmite-a. Mas, além disso, o mais importante: a universidade gera cultura que fará parte, depois, desta herança. A universidade, entáo, ao mesmo tempo, conserva, regenera e gera cultura. Assim, é necessário que ela tenha imparcialidade. Precisa ter e estimular a autonomia, a liberdade de pensamento, a laicidade. É da sua essência questionar, problematizar o mundo, a vida, a natureza e Deus. A partir da reforma universitária de Berlim, que, segundo o autor, introduziu as ciências modernas na universidade, fazendo assim coexistir, separadamente, humanidades e ciência dentro do âmbito universitário, a universidade adquiriu uma dupla funçáo na sociedade capitalista que estava em formação: a formação para a pesquisa, com a investigação crítica, que já existia a seu modo; e passa a ter também a funçáo de formar para o mercado, formar profissionais que são demandados pela sociedade capitalista e industrial crescente, criando métodos de ensino técnico, profissionalizante, especializador. Esse, diz Morin, foi o principal erro da universidade, visto que nesse momento ela perdeu a essência de sua atuação crítica, questionadora, inquiridora, para resolver demandas da sociedade, formando profissionais acríticos. Essa função deveria ser atribuída ao ensino técnico, um tipo de terceiro grau profissionalizante, e não à universidade (MORIN, 2007). 
Passando a se adequar à sociedade, a formação universitária começa a se adequar também, no geral - existem, claro, as exceçóes - ao paradigma científico-social também crescente na época, o que nos fez, chegar ao que encontramos hoje: esse processo evoluído, que ensina a separar objetos e disciplinas, não as relacionando; cuja ordem principal é eliminar tudo que possa trazer desordens. Isso resulta no conhecimento linear, hierárquico, programado, mecânico, que Morin tanto critica na atualidade.

Mas essa formaçáo hiperespecializadora encontra o seu paradoxo na dificuldade em compreender os problemas e as mazelas naturais, sociais e urbanas de hoje. Fica claro que essas mazelas não são simples ao ponto de serem resolvidas por especialistas de uma só área. Elas são complexas, globais, e as soluçóes de especialistas nunca resolvem o problema em sua raiz - são apenas soluçóes mitigatórias. Por acreditar que o principal objetivo da educação deve ser formar sujeitos críticos e autônomos, que tenham plena consciência dos problemas que enfrentaráo no seu futuro e que saibam como resolvê-los, Morin pensa a reforma do pensamento, primeiramente, nos educadores. Somente a interdisciplinaridade não é a solução.

A interdisciplinaridade precisa ir mais além, precisa se tornar transdisciplinaridade. A interdisciplinaridade, diz o autor, apenas une disciplinas, uma colabora com a outra em determinado projeto. Já a transdisciplinaridade implica um pensamento profundo, um pensamento organizador, que vai para além das disciplinas, buscando, com a colaboração de todas, organizar novas formas de pensamento (MORIN, 2007). Pensamentos que sejam conectados e circulares, dialógicos, que integrem não só as partes ao todo, mas que concebam o todo no interior de cada uma das partes. Uma forma de pensar que seja integradora, multirreferencial e diversa, que veja o mundo, a vida, a natureza e a sociedade na sua complexidade, na sua essência.

O pensamento de Morin acaba entâo numa proposta de reforma, tanto do pensamento quanto do ensino, que se organiza em três pontos principais: a) problematizar os paradigmas de conhecimento; b) substituir o pensamento linear pelo complexo; e c) buscar transdisciplinaridade (MORIN, 2007). Como já foi dito, para esse autor, a reforma deve começar na universidade, onde estão sendo formados os educadores que atuarão na formação das novas gerações. Mas como mudar o sistema universitário de modo a formar educadores conscientes da complexidade, se a universidade hoje não se apresenta, no geral, favorável a esse pensamento? Morin acredita que o caminho é, junto com uma formação crítica, buscar a autoeducação. 
A autoeducaçáo dos educadores, que os capacite a educar de acordo com as necessidades exigidas pelo futuro, é, para Morin (2007), o caminho para uma mudança de paradigmas que seria quase automática: professores se autoeducando, e depois atuando nas escolas e universidades, de modo a transformar a consciência coletiva. Esse é o principal caminho que o autor vê para a reforma. E ele se mostra esperançoso, pois o mundo de hoje, segundo ele, oferece cada vez mais possibilidades de se atingir essa autoeducação consciente da complexidade. A autoeducaçáo exige constante questionamento interior, constante problematização e crítica, e isso tudo, para ele, está na essência da atuação do educador. A cada dia que passa, o educador tem mais possibilidades de vencer os obstáculos que a sua formação e as instituiçôes lhe impóem, podendo se autoeducar e assim se formar plenamente.

Continuando seu pensamento bastante otimista e esperançoso, Morin nos lembra que esse processo não começa do zero. Ciências como a geografia, a história, as ciências da terra, a cosmologia, são multidimensionais, polidisciplinares; nelas, para se obter o real conhecimento das partes, é necessário o conhecimento do todo. Ecossistema, biosfera, ecologia são alguns conceitos que exemplificam isso. Já existem também teorias como a cibernética, a teoria da informação e a teoria dos sistemas, que permitem que, se estude e se entenda a auto-organização, a autonomia e a liberdade contidas dentro de seus processos (MORIN, 2007). Estudando e compreendendo esses processos, surge a consciência de que é necessário um pensamento complexo que lide com todas as ligaçóes e relaçóes entre várias áreas do conhecimento, que hoje são departamentalizadas. É necessário, diz Morin, que a formação capacite os cidadãos a enfrentar os problemas de seu tempo. E se os problemas se mostram complexos, nos desarmam e nos surpreendem a todo o momento, o caminho não é outro senão rearmarmonos intelectualmente.

A reforma pensada por Morin, é necessário deixar claro, não quer suprimir as disciplinas, e sim articulá-las, relacioná-las, religá-las, enfim, vitalizá-las. Ele deixou isso claro quando foi convidado pelo governo francês, em 1997, para pensar um programa de reorganizaçáo do ensino secundário francês. Sua proposta foram as jornadas temáticas, com grandes temas como Mundo, Vida, Ciência, Humanidades, Poesia, Artes, entre outros, ou seja, grandes temas que envolvem disciplinas que vemos hoje isoladas, separadas. As disciplinas, como as conhecemos hoje, só hierarquizam o conhecimento 
científico, o divide e especializa. Essa ideia de organização disciplinar surgiu nas universidades modernas e se consolidou. Morin reflete então que ela tem nascimento, maturidade e evolução. É chegada a hora, então, da decadência.

Morin é bastante otimista ao afirmar que este novo paradigma já está surgindo, um novo modelo cognitivo que não vê ordem e desordem como antagônicas e sim como complementares. Mas deixa claro também que o caminho se faz ao andar (MORIN, 2007). Morin é um filósofo, nâo um projetista. Ele dá ideias, indica caminhos, evidencia as finalidades e a complexidade dos problemas; mas deixa bem claro em sua obra que o caminho e a evolução virão a partir dos desafios que o tempo nos reservar. A reforma, então, assim como o mundo, náo pode andar sobre um caminho já traçado, visto que o futuro é incerto. A reforma precisa ser um empreendimento histórico; precisa ser compreendida pelo universo docente, e, junto com a autoeducação, estabelecer a expansão do pensamento e da consciência.

Como repete o autor a todo o momento, a premissa é: não se pode reformar as instituiçóes sem antes reformar as mentes e os espíritos (MORIN, 2003, 2007).

\section{Pensando soluçóes: Edgar Morin e os sete saberes necessários à educaçáo do futuro}

Como uma sistematização de seu pensamento, Edgar Morin (2001) elaborou o que ele chama de "os sete saberes necessários à educação do futuro". Essas ideias, resultado de sua experiência de estudos na reforma do ensino secundário francês e também de trabalho feito a convite da Unesco, abarcam os principais problemas que a educação precisa resolver para formar cidadáos capazes de enfrentar o futuro. Ele chama esses sete pontos de "buracos negros da educação", questôes que precisam ser pensadas e resolvidas o mais rápido possível, na busca de uma educação livre e autônoma. São eles:

\section{O conhecimento}

Ele também chama esse problema de "questão do erro e da ilusão". Todo tipo de ensino pressupõe apreensão de conhecimento, mas o questionamento sobre o que é ou náo conhecimento, que é de interesse de 
todos, só existe na epistemologia ou na filosofia. O autor lembra que, ao pensar o passado, sempre consideramos: "Quantos erros eles cometeram. Quantas ilusōes tinham". As pessoas acreditavam em ilusóes como conhecimentos verdadeiros. Assim, o que pensamos hoje ser conhecimento, não pode ser também ilusão? Possuímos a tendência de assumir ideias como se fossem a realidade, a filosofia sempre atenta contra isso. É necessário, ainda mais na chamada "sociedade da informação", ensinar que todo conhecimento possui risco de ser erro ou ilusão. Isso estimularia a criticidade.

\section{O conhecimento pertinente}

Um conhecimento não é pertinente só por conter grande quantidade de informação. Faz-se necessária uma organização dessa informação. Para o autor, conhecimento pertinente, que precisa ser ensinado, é o que situa as informaçóes num contexto global, geográfico e histórico, constituindo-se como um conhecimento ao mesmo tempo analítico e sintético.

\section{A condição humana}

O autor diz que em nenhum lugar é ensinado o que é a condição humana, ou seja, o que constitui a identidade de ser humano. $\mathrm{O}$ estudo das questóes humanas é desintegrado: biologia, psicologia, sociologia, entre outros. Ele defende que náo somos um espelho do universo, mas todo o universo está contido em nós. O autoconhecimento se inicia quando existe reflexão sobre nós mesmos, como dizia Sócrates, ainda na Grécia Antiga. Esse conhecimento da condição humana não deve se resumir às ciências: a literatura e a poesia, por exemplo, também precisam entrar nesse processo.

\section{A compreensão humana}

Morin diz que em nenhum lugar somos ensinados a compreender uns aos outros. Existe, segundo ele, diferença entre explicaçáo e compreensão: explicar o ser humano é tomá-lo como objeto; compreender pede a visão do sujeito, através de empatia. É muito difícil para nós compreender culturas diferentes. Costumamos sempre reduzi-las às suas características "negativas". Para se compreender o outro, é necessário primeiro compreendermos a nós próprios. A autoanálise precisa ser estimulada; se o mundo hoje está devastado, é muito por falta de compreensão. 


\section{A incerteza}

O que se ensina, segundo Morin, são só certezas. É preciso aprender a enfrentar incertezas. Uma ação nunca vai acontecer exatamente como pensada, pois ao penetrar o meio social e cultural, a ação será alterada; um exemplo claro disso é a Revolução Francesa. A consciência que tenha a incerteza como tópico acredita em ciclos e sabe que a aventura humana sempre foi desconhecida. Precisamos, como seres humanos, modificar nossos comportamentos e paradigmas a partir de conhecimentos novos.

\section{A era planetária}

Morin pensa que o ensino precisa ser conscientizador sobre o que aconteceu na história humana que levou ao desenvolvimento dessa era: o imperialismo, a dominação cultural, a escravidáo, entre outros acontecimentos importantes que resultaram na ordem social contemporânea. As guerras mundiais, a expansão das comunicaçóes e a expansão da mentalidade de mercado precisam ser compreendidas; faz-se necessário ensinar as origens desse tipo de relaçôes sociais que temos hoje, sua complexidade e suas liçóes para o futuro.

\section{A antropoética}

A ética na escala humana. Precisamos desenvolver a nossa autonomia pessoal, o nosso ser, ou seja, a nossa responsabilidade e a nossa participação no gênero humano. Isso nos conduziria a ideias de igualdade, de democracia, de solidariedade, vitais para os cidadáos do futuro, que lidarão com os problemas e a consequente mudança.

São sete pontos que, se analisados cuidadosamente, dizem respeito à vida, ao mundo, à natureza e à sociedade como um todo. Sete saberes que, se afirmados nos processos educativos, por educadores autoformados criticamente, podem vir a estruturar um novo modelo de pensamento e de organização do conhecimento, que nos levará a novos modos de vida e de relaçôes sociais. Utópico? Talvez. Mas, como diz o professor Joel Ulhôa, filósofo e ex-reitor da UFG, existem dois tipos de utopias: as que nunca serâo e as que ainda não são. Edgar Morin está certo e otimista de que sua utopia ainda não é, mas está no caminho certo para, quem sabe, se chegar a 
254 Polyphonía, v. 22/2, jun./dez. 2011

uma transformação da ordem social marcada pelo respeito a nossa essência: com liberdade e autonomia.

\section{Referências}

MORIN, E. Introdução ao pensamento complexo. Lisboa: Instituto Piaget, 1991.

MORIN, E. A cabeça bem-feita: repensar a reforma, reformar o pensamento. 8. ed. Rio de Janeiro: Bertrand Brasil, 2003.

MORIN, E. Educação e complexidade: os sete saberes e outros ensaios. 4. ed. São Paulo: Cortez, 2007.

MORIN, E. Os sete saberes necessários à educação do futuro. 3. ed. São Paulo: Cortez; Brasília, DF: Unesco, 2001.

Recebido em: 27 abr. 2012

Aceito em: 31 maio 2012 